\title{
Novelties in the field of autoimmunity-1st Saint Petersburg congress of autoimmunity, the bridge between east and west
}

Citation for published version (APA):

Dahan, S., Segal, Y., Watad, A., Azrielant, S., Shemer, A., Maymon, D., Stroev, Y. I., Sobolevskaya, P. A., Korneva, E. A., Blank, M., Gilburd, B., Shovman, O., Arnital, H., Ehrenfeld, M., Tanay, A., Kivity, S., Pras, E., Chapman, J., Damoiseaux, J., ... Shoenfeld, Y. (2017). Novelties in the field of autoimmunity-1st Saint Petersburg congress of autoimmunity, the bridge between east and west. Autoimmunity Reviews, 16(12), 1175-1184. https://doi.org/10.1016/j.autrev.2017.10.001

Document status and date:

Published: 01/12/2017

DOI:

10.1016/j.autrev.2017.10.001

Document Version:

Publisher's PDF, also known as Version of record

Document license:

Taverne

Please check the document version of this publication:

- A submitted manuscript is the version of the article upon submission and before peer-review. There can be important differences between the submitted version and the official published version of record.

People interested in the research are advised to contact the author for the final version of the publication, or visit the DOI to the publisher's website.

- The final author version and the galley proof are versions of the publication after peer review.

- The final published version features the final layout of the paper including the volume, issue and page numbers.

Link to publication

\footnotetext{
General rights rights.

- You may freely distribute the URL identifying the publication in the public portal. please follow below link for the End User Agreement:

www.umlib.nl/taverne-license

Take down policy

If you believe that this document breaches copyright please contact us at:

repository@maastrichtuniversity.nl

providing details and we will investigate your claim.
}

Copyright and moral rights for the publications made accessible in the public portal are retained by the authors and/or other copyright owners and it is a condition of accessing publications that users recognise and abide by the legal requirements associated with these

- Users may download and print one copy of any publication from the public portal for the purpose of private study or research.

- You may not further distribute the material or use it for any profit-making activity or commercial gain

If the publication is distributed under the terms of Article $25 f a$ of the Dutch Copyright Act, indicated by the "Taverne" license above, 
Review

\title{
Novelties in the field of autoimmunity - 1st Saint Petersburg congress of autoimmunity, the bridge between east and west
}

\author{
Shani Dahan a,b ${ }^{\text {a, Yahel Segal }}{ }^{\mathrm{a}, \mathrm{b}}$, Abdulla Watad ${ }^{\mathrm{a}, \mathrm{b}, \mathrm{c}}$, Shir Azrielant ${ }^{\mathrm{a}, \mathrm{b}}$, Asaf Shemer ${ }^{\mathrm{a}, \mathrm{b}}$, Dror Maymon ${ }^{\mathrm{a}, \mathrm{b}}$, \\ Yuri I. Stroev ${ }^{\text {e }}$, Polina A. Sobolevskaya ${ }^{\text {e }}$, Elena A. Korneva ${ }^{\text {e,f }}$, Miri Blank ${ }^{\mathrm{a}, \mathrm{b}, \mathrm{e}}$, Boris Gilburd ${ }^{\mathrm{a}, \mathrm{e}}$, Ora Shovman ${ }^{\mathrm{a}, \mathrm{b}, \mathrm{c}, \mathrm{e}}$, \\ Howard Amital ${ }^{\text {b,c }}$, Michael Ehrenfeld ${ }^{\mathrm{a}, \mathrm{j}}$, Amir Tanay ${ }^{\mathrm{b}}$, Shay Kivity ${ }^{\mathrm{a}, \mathrm{b}, \mathrm{j}}$, Elon Pras ${ }^{\mathrm{b}, \mathrm{g}}$, Joav Chapman ${ }^{\mathrm{a}, \mathrm{b}, \mathrm{h}}$, \\ Jan Damoiseaux ${ }^{\circ}$, Ricard Cervera ${ }^{\mathrm{k}}$, Chaim Putterman ${ }^{1}$, Iziaslav Shapiro ${ }^{\mathrm{u}}$, Luc Mouthon ${ }^{\mathrm{m}, \mathrm{v}}$, Roberto Perricone ${ }^{\mathrm{i}}$, \\ Nicola Bizzaro $^{\mathrm{p}}$, Omry Koren ${ }^{\mathrm{r}}$, Gabriela Riemekasten ${ }^{\mathrm{q}}$, Valeriy A. Chereshnev ${ }^{\mathrm{t}}$, Vadim I. Mazurov ${ }^{\mathrm{s}}$, \\ Mark Goloviznin ${ }^{\mathrm{n}}$, Victor Gurevich ${ }^{\text {s }}$, Leonid P. Churilov ${ }^{\mathrm{e}}$, Yehuda Shoenfeld ${ }^{\mathrm{a}, \mathrm{b}, \mathrm{d}, \mathrm{e}, *}$ \\ a Zabludowicz Center for Autoimmune Diseases, Sheba Medical Center, Tel Hashomer, Israel \\ b Sackler Faculty of Medicine, Tel Aviv University, Tel Aviv, Israel \\ ' Department of Medicine 'B', Sheba Medical Center, Tel Hashomer, Israel \\ d Incumbent of the Laura Schwarz-Kipp chair for research of autoimmune diseases, Sackler Faculty of Medicine, Tel Aviv University, Israel \\ e Laboratory of the Mosaic of Autoimmunity, Department of Pathology, Faculty of Medicine, Saint Petersburg State University, Russia \\ ${ }^{\mathrm{f}}$ Department of General Pathology and Pathophysiology, Institute of Experimental Medicine, Saint Petersburg, Russia \\ ${ }^{g}$ Institute of Human Genetics, Sheba Medical Center, Tel Hashomer, Israel \\ ${ }^{\mathrm{h}}$ Department of Neurology, Sheba Medical Center, Tel Hashomer, Israel \\ i Rheumatology, allergology and clinical immunology, Department of System Medicine, University of Rome Tor Vergata, Rome, Italy \\ j Department of Rheumatic Disease Unit, Sheba Medical Center, Tel Hashomer, Israel \\ k Department of Autoimmune Diseases, Hospital Clínic, Barcelona, Catalonia, Spain \\ ${ }^{1}$ Albert Einstein College of Medicine, Bronx, NY, United States \\ m Department of Internal Medicine, National Referral Center for Rare Systemic Autoimmune Diseases, Hôpital Cochin, Assistance Publique-Hôpitaux de Paris (AP-HP), Paris, France \\ ${ }^{\mathrm{n}}$ Moscow State University of medicine and dentistry, named after A.I. Evdokimov, Russia \\ ${ }^{\circ}$ Central Diagnostic Laboratory, Maastricht Univerversity Medical Centre, Maastricht, The Netherlands \\ p Laboratory of Clinical Pathology, San Antonio Hospital, Tolmezzo, Italy \\ q University Hospital Schleswig-Holstein, Campus Lübeck, Department of Rheumatology, Lübeck, Germany \\ ${ }^{\mathrm{r}}$ Faculty of Medicine, Bar-Ilan University, Safed, Israel \\ s Saint-Petersburg State University, North-Western State Medical University n.a. II. Mechnikov, Saint-Petersburg, Russia \\ ${ }^{\mathrm{t}}$ Institute of Immunology and Physiology, Ural Branch of the Russian Academy of Sciences, Yekaterinburg, Russia \\ u 24 Medhelp - clinical diagnostic center, St. Petersburg, Russia \\ v Faculté de Médecine, Université Paris Descartes, Sorbonne Paris Cité, Paris, France
}

\section{A R T I C L E I N F O}

\section{Article history:}

Received 24 July 2017

Accepted 30 July 2017

Available online 14 October 2017

Keywords:

Autoimmunity

Human papilloma virus (HPV)

Alzheimer's disease (AD)

Intra venous immunoglobulins (IVIG)

Paraneoplastic neurological syndrome

Systemic lupus erythematosus (SLE)

Anti-phospholipid syndrome (APS)
Rheumatoid arthritis (RA)

Anti-citrullinated protein antibody (ACPA)

Vitamin D

Rheumatoid factors (RF)

Anti dense fine speckled (DFS) antibodies

Anti-nuclear antibodies (ANA)

Anti-neutrophil cytoplasmic antibodies (ANCA)

$B$ regulatory (Breg) cells

\footnotetext{
* Corresponding author at: The Zabludowicz Center for Autoimmune Diseases, Chaim Sheba Medical Center, Tel-Hashomer 52621, Israel.

E-mail address: shoenfel@post.tau.ac.il (Y. Shoenfeld).
} 


\section{Contents}

1. Autoimmune diseases - diverse clinical aspects . . . . . . . . . . . . . . . . . . . . . . . . . . . . . . . . . . . . . . . 1176

2. The pathophysiology of autoimmune diseases . . . . . . . . . . . . . . . . . . . . . . . . . . . . . . . . . . . . . . . 1177

3. Systemic sclerosis, vitamin D, lupus and APS . . . . . . . . . . . . . . . . . . . . . . . . . . . . . . . . . . . . . . . . . . . 1178

4. Factors in autoimmunity and how to overcome them . . . . . . . . . . . . . . . . . . . . . . . . . . . . 1179

5. Regulatory and diagnostic autoantibodies, thyroiditis and microbiome . . . . . . . . . . . . . . . . . . . . . . . . . . . . . . . . . 1180

Summary . . . . . . . . . . . . . . . . . . . . . . . . . . . . . . . . . . . . . . . . . . . . 1181

Acknowledgements . . . . . . . . . . . . . . . . . . . . . . . . . . . . . . . . . . . 1181

References . . . . . . . . . . . . . . . . . . . . . . . . . . . . . . . . . . . . . . . . . . . . . . 1181

This special issue of Autoimmunity Reviews focuses on the 1st Saint Petersburg congress of Autoimmunity held in Saint Petersburg, Russia, on 30 June-2 July 2017. The theme of the congress "The bridge between east and west", aims to describe how knowledge and collaboration can cross all previous boundaries in our globalized scientific community today. With this in mind, an exciting program was generated, with novelties in the fields of pathogenesis, diagnostics and clinical aspects of autoimmunity presented by leading Autoimmunologists from around the world including Russian experts. The amazing city of Saint Petersburg was the perfect frame for intense and vibrant discussions, with an inspiring atmosphere of medical science infused with the magical surroundings of a city designed to build bridges.

\section{Autoimmune diseases - diverse clinical aspects}

Rarely does the scientific community dedicate adequate room for a principal discussion on the philosophy of medical research, namely the significance of a holistic oriented approach in the research of human biology and specifically in deciphering autoimmune diseases [1]. Poletaev et al. compared the human organism to a tremendous orchestra, combining in harmony the sounds of various instruments to create a beautiful Symphony. Modern research, he explained, is too often focused on singular components - a certain gene, a specific protein, or a single organ [2]. This is akin to attempting to recreate the symphony by analysing solely the role of the violins. When addressing complicated processes such as the pathophysiology and attenuating factors of autoimmune diseases, no doubt research should be guided by a holistic view [3].

A fine example of the importance of a holistic approach to disease research can be found in the case of Alzheimer's disease (AD), where disease pathogenesis is still largely unclear and appears to regard to multiple aspects of medical science. Tanay et al. reviewed novel autoimmune aspects of $\mathrm{AD}$, relating to aberrancies in the innate immune system as well as the adaptive immune system. The pathologic processes mediated by the innate immune system include complement mediated cell lysis of neuronal cells containing $\beta$ amyloid $(A \beta)$ oligomers [4], activation of chemokines and overexpression of toll like receptor- 4 [5]. The involvement of the adaptive immune system is manifested mainly by a changes in balance of various T lymphocyte populations [6]. All these phenomena are negatively correlated with cognitive test results [7]. In light of the suggested role of the immune system in the pathogenesis of $A D$, various immunotherapeutic strategies have been examined as possible treatments. Active immunization with $A \beta$ components has yielded promising results in several small scale studies, though in some studies severe adverse effects were reported [8]. Passive immunization is also currently explored in various phase 2 and phase 3 clinical trials. Finally, Intravenous high doses of IgG (IVIG) was tested. While recent trials failed to demonstrated clinical benefit, an additional phase III trial is still ongoing [8].

Another important example of the involvement of autoimmune dysregulation in pathological processes of the central nervous system is the issue of Paraneoplastic Neurological syndromes (PNS). PNS are a group of immune-mediated syndromes effecting the central and/or peripheral nervous system, the neuromuscular junction or the muscles themselves $[9,10]$. Autoantibodies (Aab) may be detected in the serum and cerebrospinal fluids of PNS patients [11]. These Aab may be directed against intra-neuronal antigens, as in 'classical' PNS, believed to be T cell mediated and less responsive to therapy. Aab may also present against antigens on neuronal cell membranes or receptors, as in 'non-classical' PNS, considered to be antibody-mediated, and responsive to immunotherapy if treated early [12,13]. Kivity et al. analysed the results of 4010 PNS Aab tests conducted in Sheba medical Center in Israel between 2002 and 2016. 45 PNS patients were detected, and there was a positive correlation between antibody titers and the likelihood for cancer diagnosis. The most common cancer diagnoses were small-cell lung and ovarian malignancies. During the follow-up time, mortality was $22.8 \%$ in the 'classical' group, compared to none in the 'non-classical' group.

While PNS vividly demonstrates an important link between cancer and autoimmunity, it is not the only instance where the two are intertwined. Such is the case of the Epstein Barr virus (EBV), which is known to be involved in the pathogenesis of SLE as well as the development of several malignancies. A recently published novel theory regarding the role of human papilloma virus (HPV) in the pathogenesis of lupus $[14,15]$ suggests HPV may provide a similar model. Segal et al. point to the increased prevalence of HPV infection among lupus patients, and offer this association might be one of causation, referring to the potentially similar causative relationship between EBV and lupus. The suggested mechanism is that of molecular mimicry [16], and accordingly the authors address their findings compiling of a vast similarity between HPV peptides and human proteins associated with lupus. This similarity may lead to a cross reaction of the immune system, causing it to attack the similar human proteins upon exposure to the virus, specifically in the setting of a genetic predisposition for autoimmunity [17]. This proposed relationship between HPV and SLE may have significant implications on young women exposed to HPV infection as well as the HPV vaccines. 
Further addressing implications of autoimmunity on the female patients, updates of the pathophysiology and developing therapies for obstetric anti phospholipid syndrome (APS) were presented. In the center of discussion was the emerging understanding of the role of Antiphospholipid antibodies (aPL), not just as markers of pregnancy morbidity but rather as active components of the pathological process, demonstrated to directly bind trophoblastic cells and modify their differentiation, syncytialization, invasiveness. In addition, by their internalization in trophoblastic cells, aPL can cause accelerated cell death with the consequent release of cells debris [18]. Conventional treatment, which drastically improved morbidity, is compiled of low molecular weight heparin and low dose aspirin. However, up to $20 \%$ of the patients still have pregnancy failure. For patients with recurrence despite treatment, therapies such as intravenous immunoglobulins, plasmapheresis, and corticosteroid treatment may offer additional benefit [19]. Novel experimental therapies include hydroxychloroquine [20], and statin therapy, which has recently been shown to improve outcome in patients with preeclampsia [21].

Naturally, obstetric APS is but one example of a field transformed by novel research. A similarly important example was presented in a succinct review of new biomarkers for the diagnosis and management of Rheumatoid Arthritis (RA). Unfortunately, a significant proportion of RA patients is negative for the well-known, 'traditional', biomarkers - IgG-IgM-IgA rheumatoid factors (RF) and IgG against citrullinated peptides (ACPA) - making their diagnosis more challenging. However, novel biomarkers are presenting partial possible solutions. Among those is anti-CarP, an antibody against carbamylated amino acids, a post-transcriptional modification that, like citrullination, is associated with inflammation and smoking. Anti-CarP Antibodies can be associated with a more erosive RA, where shown to predict the onset of disease [22,23], and may assist in differentiating elderly onset RA from polymyalgia rheumatica [24]. Additional emerging biomarkers may be recognized in a sub population of antibodies against Peptidylarginine deaminase (PAD), the enzyme family responsible for citrullination. RA patients positive for antibodies cross reacting to PAD3 and PAD4 were reported to display a higher radiographic severity $[25,26]$. These new biomarkers are promising diagnostic/prognostic tools for a personalized medicine in the RA field.

However, while biomarkers are crucially important for diagnosing the ill, they may be equally important for recognition of the healthy. Shovman et al. summarized a recent research designed to characterize such a biomarker - the intriguing anti dense fine speckled (DFS) antibodies [27]. Anti DFS antibodies are part of the anti-nuclear antibodies (ANA) panel used for preliminary screening for systemic autoimmune rheumatic diseases (SARDs). However, several studies suggest anti DFS antibodies to be more prevalent among ANA positive healthy individuals $(\mathrm{HI})$ than among patients with SARDs [28]. Shovman and colleagues assessed the prevalence of anti DFS antibodies among 50 SARDs patients and $92 \mathrm{HI}$. The prevalence of monospecific anti-DFS70 antibodies was significantly higher in the HI group than in the SARDs patients. This data confirms that mono-specific anti-DFS70 antibodies are a strong discriminator between ANA positive $\mathrm{HI}$ and SARDs patients. Thus, their incorporation in diagnostic algorithms may prevent unnecessary financial costs for health systems, as well as needless stress for patients, changing the current paradigm of ANA based diagnosis.

Diagnostic paradigms are shifting in other fields as well, as was clear from the presentation of the results from a groundbreaking multicenter study, concerning the current accepted paradigm for diagnosis of anti-neutrophil cytoplasmic antibodies (ANCA) associated vasculitis (AAV) [29]. The study was designed to evaluate the relevance of indirect immunofluorescent detection (IIF) of ANCA, which is the common accepted screening tool for AAV [30]. In this study IIF was compared to antigen-specific immunoassays for MPO- and
PR3-ANCA, based on samples of 251 of vasculitis patients and 924 sample of patients suspected of vasculitis, in which AAV diagnosis eventually was rejected. The data obtained in the study revealed substantial heterogeneity in ANCA IIF testing [31], and further clearly indicate that for ANCA screening in the context of small vessel vasculitis, antigen-specific immunoassays (MPO and PR3) are preferred over ANCA IIF. Low positive results should be confirmed by another antigen-specific test, while negative results do not exclude a diagnosis of AAV and, in case of a high pre-test probability, even may warrant a second opinion test. Based on the results obtained, a new international consensus, with further details, will be available in the very near future.

Updating on novel future directions in autoimmune research is crucial, however similarly important is constant learning of the enormous corpus of well-established data. To this end, Toubi et al. provided a well-rounded review of the roles of B cells in autoimmunity, addressing their well-known roles, as antibody secreting cells and antigen presenting cells, as well more recently discovered roles. With regards to the 'traditional' role of B cells in autoimmunity it is worth mentioning factors such as B lymphocyte stimulating factor (BLyS) and IL-6, which are responsible for the breakdown of B cell self-tolerance and already serve as targets of certain novel therapies $[32,33]$. However, perhaps most interesting is the identification of a relatively new subset of $B$ cells responsible for maintaining self-tolerance, the B regulatory (Breg) cells [34]. Evidence suggest Breg cells to play a role in the pathogenesis of SLE, ANCA-related vasculitis, rheumatoid arthritis and multiple sclerosis [35,36]. Characterization of Breg cells is ongoing, with recent findings including the expression of CD72 and semaphorin3A (Sema3A), both induced suppressive effects on B cell activity [37,38]. Many of the current efforts are invested in classification of specific subsets of Breg cells $[39,40]$ which provide ways to target these cells and harness them as therapeutic tools.

\section{The pathophysiology of autoimmune diseases}

Autoimmunity is a complex process, shaped by numerous attenuating and instigating factors, well described in concept of the mosaic of autoimmunity, initially termed by Shoenfeld et al. in 1989 [41]. One such noteworthy factor is vitamin $\mathrm{D}$, which has an intriguing relationship with autoimmunity, as reviewed by Azrielant et al. Vitamin D deficiency is common in the general population, and even more so among autoimmune patients [42]. There is robust epidemiological evidence regarding this association, as well as molecular evidence supporting existence of vitamin D receptors on different cells of the immune system [43]. Possible explanation for the association between vitamin D deficiency and autoimmunity were discussed, including steroids usage, common genetic pathway, sunlight avoidance behavior in SLE patients, and vitamin D as a negative acute phase reactant. However, none of these explanations could fully explain the association alone. Interventional studies on this subject also show promising results. The authors concluded that vitamin D supplementation as safe and beneficial in autoimmune patients, and therefore is advised for them [44].

Moreover, the question of what are the proper medical interventions for patients with autoimmune diseases extends much further than the issue of vitamin $\mathrm{D}$, troubling doctors throughout the field of autoimmunity. An important step towards devising a thorough answer, rests in the development of accurate pre-clinical and clinical biomarkers in systemic autoimmune rheumatic diseases. One such prominent example is RA [45], which is currently known to have various markers eluding to the stages of symptomatology, as well as the interactions of environmental, genetic and immune factors that determine disease progression, manifestations and comorbidities [46]. Some such markers can be found prior to clinical manifestations of the disease, enabling early diagnosis and optimal treatment. The 
treatment for RA has been revolutionized in recent years, both through the introduction of new biological agents, and adaptation of treat to target (T2T) strategy. Current strategy supports initiating treatment as early as possible to prevent irreversible joint damage and risk of comorbidity; however, this may lead to over-treatment, and in some cases to adverse effects. Adaptation of personalized medicine (PM), according to the patient's genes and unique environmental risk factors could help solve this issue. PM aims to sub-divide patients into different categories based on their "molecular make up", by using objective biomarkers [47]. The ideal biomarker would be safe and easy to measure, sensitive and specific for the disease, cost efficient, provide more information than routine clinical and laboratory examinations, and modifiable with treatment. The application of biomarkers can help diagnose RA patients in early stages of the disease, better assess disease activity, and predict response to treatment. Some of these markers, such as: RF, ACPA, C-reactive protein, and erythrocyte sedimentation rate (ESR), have already been incorporated into the revised classification criteria of RA. Unfortunately, there are currently no baseline definitions for biomarkers that can be used in individually tailored treatment regimns, of both DMARDs or biologic agents, and no predictors for successful dose reduction or discontinuation of biologic medications $[48,49]$. In the near future, researchers expect that new biomarker panels will become available, and used routinely in RA patients.

While intrinsic biomarkers may enable customization of medical treatment to some extent, with hopes of improving medical care, an equally important factor in the pathogenesis of autoimmunity is extrinsic factors, which may attenuate or aggravate diseases, and often are triggers for relapse or exacerbation. An analysis of such precipitating factors as well as different treatment strategies was reviewed by prof. Ricard Cervera for Catastrophic antiphospholipid syndrome (CAPS). CAPS is characterized by small vessel occlusions involving multiple organ systems, that develops over a very short period of time. The diagnosis is confirmed by presence of antiphospholipid antibodies (aPL), usually in a high titers [50,51]. The CAPS Registry documents the clinical, laboratory and therapeutic data of all published cases with CAPS, as well as of many additional patients whose data has been fully registered. The most recent analysis including $500 \mathrm{pa}-$ tients [52], in which precipitating factors were identified in $65 \%$ of the episodes: most frequently infections (49\%) of the respiratory tract (33\%), urinary tract (19\%), and skin (13\%). The clinical picture was characterized by involvement of the kidneys (73\%), with variable degree of renal failure, and lungs (60\%), in the form of acute respiratory distress syndrome or pulmonary embolism (26\%). Up to $56 \%$ of patients had central nervous system manifestations due to stroke or encephalopathy. The heart was affected in half of the episodes, mainly due to myocardial infarction or valvulopathy. Death occurred in $37 \%$ of episodes.

In term of treatment, data for the CAPS Registry showed higher recovery rate was achieved by the combination of anticoagulation plus glucocorticoids plus plasma exchange; this treatment, and/or IVIG instead of plasma exchange, seems to be responsible for the reduction in mortality rate in recent years. Cyclophosphamide treatment did not demonstrate an additional benefit. Glucocorticoids treatment alone was related to a lower rate of recovery.

\section{Systemic sclerosis, vitamin D, lupus and APS}

De Carolis and colleagues presented the role of HLA DQ2 DQ8 and vitamin $\mathrm{D}$ in recurrent miscarriages. The etiopathogenesis of infertility (primary infertility and recurrent spontaneous abortion - RSA) includes genetic and anatomic abnormalities, autoimmune disorders (AD) and low vitamin D levels [53-55]. Unexplained reproductive failure accounts for $50 \%$ of the infertile conditions, and it involves immune-mediated pathways [55]. Vitamin D has immunoregulatory properties, and its deficiency is highly prevalent in patients with $\mathrm{AD}$ and was also associated with increased risk of pregnancy complications [55,56].

The HLA class II genes are susceptibility genes for AD [56], with HLA-DQ2 and/or HLA-DQ8 alleles characterizes celiac disease (CD); in recent years, significant association between $C D$ and reproductive failure was reported [56]. However, scarce data are available pertaining to the determinants of genetic susceptibility to primary infertility and recurrent spontaneous abortions (RSA). The researchers analysed the HLA class II alleles distribution and serum levels of 25hydroxyvitamin $\mathrm{D}[25(\mathrm{OH}) \mathrm{D}]$ in a cohort of 175 women with primary infertility or RSA and AD, with the exclusion of CD patients. In this study, infertile women had lower vitamin D levels compared to women with RSA, suggesting that reduced $25(\mathrm{OH}) \mathrm{D}$ levels represent an evidence of immune dysregulation, and may characterize women with primary infertility due to "autoimmune mechanisms" of the pregnancy failure [57]. In addition, women with AD were prevalent in the group of primary infertility, and autoimmune thyroiditis (ATD) was the predominant AD condition. These findings are supported by evidence of the role of thyroid function in the pathogenesis of many autoimmune disorders including infertility [55]. Similar distribution of HLA class II genes was seen both in infertile and RSA women, and a higher proportion of HLA-DQ2 positive women among infertile women with ATD compared to infertile women without ATD. These preliminary data suggest a potential association between reduced serum 25(OH)D and HLA class II susceptibility genes in autoimmune women with infertility.

This suspected relation between vitamin D levels, genetic susceptibility and infertility may serve as a reminder that autoimmunity is a medical field regarding all clinical specialties. Indeed, while it is probably true that no doctor can give proper medical care without being familiar with the central dogmas of autoimmunity, the importance of the field is accentuated among pediatricians, which often encounter autoimmunity at its first manifestations. Chereshnev et al. discussed the diagnosis of autoimmune connective tissue diseases in children. The prevalence of autoimmune connective tissue diseases in Russia is growing in recent decades [58] and the most common autoimmune disease in children is juvenile idiopathic arthritis (JIA), which prevalence is estimated to be around 0,4\% [59]. Systemic autoimmune involvement in children, is much less common than merely autoimmune lesion of joints, and the prevalence of systemic lupus erythematosus (SLE) in children is $9.38-10.08$ per 100,000 [60]. For the differential diagnosis of autoimmune diseases, the determination of autoantibodies is commonly used. Antinuclear antibodies (ANA) against ribonucleoproteins are the most common antibodies in patients with diffuse connective tissue diseases; the most sensitive method for their detection is indirect immunofluorescence reaction for antinuclear factor. ANA was detected in all examined SLE children; however, the diagnosis of JIA may be quite difficult. Although in adults with rheumatoid arthritis, methods for the detection of antibodies against citrullinated proteins are widely used and have high sensitivity and specificity [61], the prevalence of these antibodies in children with JIA is much lower. The researchers examined more than 400 children with JIA, and antibodies to citrullinated proteins were found in $18 \%$ of cases, and ANA were detected in $60-75 \%$ of cases, depending on the variant of the disease. However, the antibody titer in most children rather low, and these antibodies are not specific for JIA. Thus, further search of informative laboratory tests for differential diagnostics of autoimmune diseases of connective tissue in children is needed.

An additional aspect of improving diagnostics for autoimmune diseases is the potential to use specific diagnostic markers in order to design selective, targeted therapies. The concept is being widely explored in several disease models, among those SLE. Targeted therapies in SLE would hopefully be associated with improved therapeutic efficacy as well as fewer side effects $[62,63]$. The recognition of the role of the innate immune system in the pathogenesis of SLE, and in particular 
the role of macrophages, suggests new therapeutic targets. The researchers examined the effect of GW2580, an oral kinase inhibitor of CSF-1R signaling, in the lupus prone MRL-lpr/lpr mouse strain, with daily treatment from 10 to 16 weeks of age [64]. GW2580 treatment did not modulate circulating immunoglobulin or IgG anti-DNA levels. Nevertheless, treated mice did not exhibit the increasing levels of proteinuria found in the controls. The treatment was associated with improved glomerular pathology, a protective effect likely mediated through the effect of the drug on macrophages, and reduced cytokine levels. Bruton's tyrosine kinase (BTK) is important in key intracellular signaling pathways in both $B$ cells and macrophages. The researchers explored the use of a novel BTK inhibitor, BI-BTK-1, in lupus nephritis animal models, and found that in 129/svJ mice, preventive administration of BI-BTK-1 prevents proteinuria and renal dysfunction in a dose dependent manner [65]. Treatment also decreases complement deposition and prevents renal histopathological damage. Further studies on this subject are being held currently.

Further novel research into the pathogenesis of SLE relates to the association between the microbiome and SLE. Alterations in the human gut and oral mucosa microbiota have been recognized as an important environmental factor in autoimmune diseases, and specifically in SLE patients. Animal model studies have demonstrated distinct bacterial microbiota in SLE prone mice, and their microbiota changed with disease progression and severity. Other factor that influence the microbiota diversity are gender, age and genetics [66]. A clinical study investigating the characteristics of the gut microbiota in lupus patients compared to healthy controls found that in medication free patients, the composition of gut microbiota was similar in the SLE group regardless of clinical manifestations or anti-dsDNA antibodies levels [67]. In term of the microbiota composition, the Firmicutes/ Bacteroidetes ratio (F/B ratio) was significantly lower in SLE patients compared to controls, even during disease remission, and nine genera of gut microbiota were classified as SLE-related microorganisms [67, 68]. Subgingival microbiota also plays a role in SLE, and was found to be different in lupus patients with and without chronic periodontitis, as well as when compared to non-autoimmune individuals. Lupus patients with chronic periodontitis have a higher subgingival bacterial load, reduced microbial diversity and higher prevalence of pathogenic strains of bacteria. Also, the severity of periodontitis is associated with the severity of SLE disease [69].

These findings suggest that manipulation of the microbiota may be beneficial in patients with SLE.

\section{Factors in autoimmunity and how to overcome them}

Genetic factors play an important role in the mosaic of autoimmunity. Genome-wide association studies (GWAS), as was beautifully reviewed by Pras el al, are the main method for detecting genes predisposing to autoimmune diseases. To date, hundreds of GWAS studies have been performed for a wide variety of autoimmune disorders and these have resulted in the identification of hundreds of genes [70]. The function of these genes is highly variable and includes chemotaxis, lymphocyte activation, innate defense, adaptive immunity regulation, inflammatory mediators, autophagy, barrier function, NF-kB activation or inhibition, antimicrobial peptides and phagocytosis. However, above all, these studies emphasize the striking role of the HLA system in the pathogenesis of these disorders [71]. Despite the small fraction of heritability discovered, the genes identified until now enhance our understanding regarding the biological pathways involved in the pathogenesis of these diseases, pathways that may serve as therapeutic targets in the future [72].

Another factor comprising the mosaic of autoimmunity is the human immune system and its diverse components. In the recent years, it has been demonstrated that the complement system participate in modulating adaptive immunity and in bridging innate and adaptive responses [73]. Dysregulation of the complement system has been involved in the pathogenesis of several autoimmune diseases, such as systemic lupus erythematosus, vasculitides, Sjögren's syndrome and antiphospholipid syndrome $[74,75]$. Involvement of complement in the pathogenesis of RA was confirmed in animal models of arthritis; mice deficient for complement proteins are protected against the development of collagen-induced arthritis and administration of the anti-C5 monoclonal antibody prevents the onset of this arthritis. In the last decade anti-TNF agents have shown to be effective for the treatment of both RA and psoriatic arthritis and some studies suggest that the interaction between TNF $\alpha$ and complement system may contribute to the pathogenesis of these diseases [76]. Because of its functions, the complement system is an attractive therapeutic target for a wide range of inflammatory and autoimmune diseases. At present, data from clinical trials suggest that the modulation of the complement system could constitute a viable strategy for the treatment of autoimmune conditions in the decades to come [77].

The novel role of several nutritional components of the human diet in the development of autoimmune diseases was presented by Dahan et al. [78]. Dietary habits have a crucial influence on human health. Moreover, an individual's lifestyle choices can greatly influence the progression and manifestation of chronic autoimmune rheumatic diseases. In light of these effects, it makes sense that the search for additional therapies to attenuate such diseases would include investigations into lifestyle modifications. When considering the complex web of factors that influence autoimmunity, it is not surprising to find that several dietary elements are involved in disease progression or prevention. Data suggests that these ingredients substantially affect both the innate and adaptive branches of the immune system. Whereas salt seems to promote inflammation via several mechanisms, consumption of curcumin, capsaicin, chocolate and resveratrol might attenuate immune hyperactivity, and consumption of omega-3 fatty acids and coffee seem to have ambivalent effects on immunity. The human microbiome seems to be emerging as the common denominator underlies the strong influence of these dietary bioactive compounds on the immune system. The data presented by Dahan et al. are sufficient to determine that these factors constitute a novel and under-explored aspect of autoimmunity that will hopefully inspire further investigation.

Stress is yet another environmental factor considered to influence the reactions of both immune and nervous system [79,80]. Korneva et al. [81] have showed several mechanism by which this interactions are achieved. For example severe stress causes a decrease in lymphoid cells reactions to signals such as IL-1, as well as inhibition of natural killer (NK) cells activity $[79,82]$. Further study is requested in order to allow better understanding of this factor in the mosaic of autoimmunity.

Adjuvants are also known to play a key role in the complex interaction of environmental factors in the pathogenesis of autoimmune diseases. Watad et al. [83] have beautifully reviewed the role of adjuvants in inducing autoimmunity and lymphomas. Aluminum is the main culprit in human vaccines such as human papilloma virus (HPV) and hepatitis B virus (HBV) vaccines [84]. Supporting data has been collected from several animal models regarding immunologic responses, resulting autoimmunity, following injection of those vaccines $[85,86]$. However, not only aluminum is to blame, as silicone breast implantations have been recently implicated in the development of lymphoproliferative disorders. The chronic stimulus of $B$ cells has been associated as the main mechanism of this process. To tie up the loose ends it has been reported that higher rates of lymphomas has been observed among patients with autoimmune diseases [87].

Not only lymphoma is highly associated with autoimmune diseases, as was beautifully presented by Michael Ehrenfeld, who discussed the issue of RA \& malignancy and the impact of TNF inhibitors on lymphomas and skin cancers. An interesting result was obtained from British registry regarding the rates of incident malignancy in RA patients with a prior cancer. The cumulative adjusted IRR for recurrence of 
malignancy was found to be 0.55 , thus confirming no increased risk of incident malignancy (excluding melanoma) [88].

\section{Regulatory and diagnostic autoantibodies, thyroiditis and microbiome}

In this meeting, a substantial attention was given to the contribution of serological tests to the diagnosis and classification of autoimmune diseases. In the recent years, the scenario has changed enormously due to the reported increased incidence in autoimmune disorders, the tremendous evolution and the increased complexity of immunoassays and of analytical instruments, and the consolidation of autoimmunology in clinical laboratories [89]. As a consequence, manual methods have almost disappeared and automation has taken over, providing for higher analytical throughput in order to meet clinical needs and growing demand for autoantibody testing. Aside from automation in slide preparation of ANA test that has certainly improved assay standardization compared to the manual method, automated computerized systems for reading and interpretation of immunofluorescence (IIF) ANA have been recently developed. These systems show an acceptable correlation with manual microscope reading, allowing for automated classification of samples (with a high efficiency in discriminating between positive and negative result), automated quantification of autoantibodies, significant reduction in assay imprecision, and implementation of a quantitative internal quality control system. These new methods showed analytical performance superior to the manual IIF method also in detecting ANCA. The elevated sensitivity of the novel automated immunoassay method, indicate that MPO and PR3 ANCA screening could be executed by using these new analytical technologies [90]. Thus, as in other fields of laboratory medicine, the trend towards automation and networking of laboratories may represent a powerful incentive for standardization and harmonization, useful for accreditation or certification purposes [91]. In recent years, automated immunoassay monoplex platforms have progressively taken the place of manual methods and enzyme immunoassays: the so-called batch analysis is progressively replaced by random-access methods that provide faster results and reduce workload. In this contest, a prominent role is taking the use of automated analytical platforms based on chemiluminescent (CLIA) technology which is characterized by immunochemical reactions with significantly shorter execution times than other types of immunoassay. The key advantages of CLIA analytical methods reside in the wide dynamic range, high signal intensity, absence of interfering emissions (i.e. high specificity), rapid acquisition of the analytical signal, high stability of reagents and their conjugates, low consumption of reagents, random access, reduced incubation time, full compatibility with immunology assay protocols (homogenous or non-homogenous). However, notwithstanding the great improvement in random access monoplex testing, the near future is likely to see multiplex assays as the prevalent technology for antibody detection. Indeed, multiplex proteomic technology is considered to be an optimal solution for the simultaneous detection of different autoantibodies, allowing the autoantibody profiling of autoimmune patients, either for diagnostic or prognostic purposes, or even for prevention of autoimmune diseases. Some of these immunoassays (planar and non-planar microarrays) may contribute to overcoming some drawbacks of the monoplex immunoassays (time expenditure, costs, lack of harmonization, volume of reagents and samples, turnaround time, etc.). In addition, the autoantibody profiling of patients with an autoimmune disease provided by these systems may be useful for following the concentration of specific autoantibodies, which may display different trends over time [92]. Finally, with the constant development of more complex tests such as genomic- and proteomic-based assays, clinical interpretation of test results will become increasingly difficult. Since these processes will require highly qualified skills, an important role in this scenario is taken by the laboratory autoimmunologist, whose task is not only to govern the analytical phase, but also to help clinicians in correctly choosing the most suitable test for each clinical situation and provide consultancy support.

Gilburd et al. has brought forth evidence of autoantibodies that can serve as highly specific biomarkers in confirmation of IMNM diagnosis in statin-exposed patients [87]. Antibodies directed against 3-hydroxy-3-methylglutaryl-CoA reductase (HMGCR), an enzyme of the mevalonate pathway involved in cholesterol synthesis represent a characteristic serological feature of statin-exposed and statin-unexposed patients with immune-mediated necrotizing myopathy (IMNM) [94]. Gilburd et al. evaluated the existence of anti-HMGCR antibodies in statin-exposed patients with suspicion for IMNM and in two control groups: healthy subjects and patients with different autoimmune rheumatic diseases. Using the Enzyme-Linked Immunosorbent Assay (ELISA) and Chemiluminescence Immunoassay (CIA) assays they have found the presence of anti-HMGCR antibodies in samples from statinexposed patients with suspicion for IMNM [93].

Current laboratory techniques used in the autoimmunity field, such as High-technology automated analytical systems, were the focus of a thorough review given by Alexandrova et al. [95]. These biomarkers are an important tool for prevention, early diagnosis, assessment of disease activity, progression rate, clinical laboratory subtypes of autoimmune diseases, prediction of the efficiency of therapy and the risk of adverse events during treatment [96], and deciphering the key pathogenetic mechanisms of autoimmune diseases could identify the molecular and cellular biomarkers that might be used as therapeutic targets hence improving both patient life span and quality [97,98].

An important attention was also given to autoimmune thyroiditis (AIT), showing that nowadays, AIT became the most prevalent autoimmune and most frequent endocrine disorder, especially among females. Current diagnostic criteria for AIT formulated by Japanese Thyroidological Association [134]. For diagnosis is enough to have one clinical (diffuse thyroid enlargement or hypothyroidism - with no other reasons) and any one of lab criteria [antibodies $(A B)$ to peroxidase either thyroglobulin, or biopsy, or diffuse non-homogenous thyroid image]. Although in general AB in AIT may vary in biological effects, anti-peroxidase $A B$ level correlate to its severity. The mosaic of AIT includes genetic, infectious and adjuvant-like factors [103], but excessive intake of iodine is of utmost importance. A 25-years prospective followup for persons experienced massive iodine prophylaxis while being in Chernobyl area showed that prevalence of AIT and levels of anti-thyroid $A B$ in them is much higher than in local residents of the same age who never visited Chernobyl. AIT display comorbidity with rheumatologic diseases and within autoimmune polyendocrine syndromes. Churilov et al analyzed a 15,000 cases database and found comorbidity of AIT and juvenile dyspituitarism (aka: Simpson-Page syndrome, obesity with rose striae) - $26,5 \%$ vs $1,5 \%$ in general population as well as nonsyndromal connective tissue dysplasia of marfanoid phenotype (with marfanoid stigmata in $90 \%$ of such patients). This comorbid combination tends to progress with age into early complicated metabolic syndrome [10]. The mechanism of this transgression in such individuals is related to systemic excess of TGF-beta, leptin, prolactin and several pro-inflammatory cytokines with decrease of adiponectin [104].

Big data, as a game changer in research in the field of autoimmunity, disserved a special attention during this meeting. Prof. Amital and his group summarized their experience in the use of computerized medical records for research purposes. The resultant accessibility to this information mandates careful adaptions of ethical guidelines regarding the handling of clinical data. At the same time, it grants a unique opportunity to explore the clinical nature of health and disease in large populations across all of society's strata, socioeconomic levels, ethnicities, and geographic locations regardless of their vicinity or distance to tertiary care centers. Analysis of large databases allows us to learn the public's behavior towards medical services and to investigate how medical interventions affect outcomes overtime [106-109]. Moreover, the interaction between different co-morbidities can be better understood by large population studies. The huge numbers of patients involved in 
these studies provide a good model of multivariate analysis, a statistical tool that by following proper population adjustments underlines the true independent associations between different conditions. Nevertheless, the limitations of these studies should be borne in mind, such as in-built imprecision of diagnoses, incompleteness of the medical data, and the fact that these databases were initially planned for clinical and not investigational use.

Experts in the field of microbiome research, reported elegantly the relevant advancements in this filed, showing the rapid increase of diseases that are linked to changes in the microbiome [110]. Recently, several studies have begun to characterize the changes that occur to the microbiome in autoimmune diseases [111]. Unraveling the exact mechanisms by which shifts in microbial community composition affect the pathogenesis of autoimmune diseases may facilitate the identification of populations at risk, and enable the development of new approaches for patient-tailored early intervention. Some of the known cues affecting the function of the immune system, such as genetics, gender, pregnancy and diet, exert their effects, at least in part, by influencing microbiota composition and activity. One such example are helminths, parasitic worms, which have been shown to modify the immune response in their hosts in order to survive [112-115]. Consequently, several successful trials using helminthes as treatments for autoimmune patients have been reported. The helminth derivative, phosphorylcholine (PC), was discovered as an immunomodulatory compound when presented on a carrier molecule. Blank et al. have recently showed that when a conjugate of Tuftsin and PC, termed TPC, is administrated to mice with autoimmune disease, it attenuates the disease development in three animal models: SLE in lupus prone mice (NZBxW/F1) [116]; collagen induced arthritis (CIA) in DBA mice [117] and in dextransulfate sodium-salt induced colitis [118]. This inhibition was associated with increased levels of the anti-inflammatory cytokine IL-10, decreased levels of the pro-inflammatory cytokines TNF, INF, IL-1, and IL-17, followed by an expansion in the number of T regulatory cells. Importantly, we found that TPC treatment altered the gut microbiota composition of the mice. Using these bacterial biomarkers, all TPC-treated CIA mice were classified as healthy. Thus, Blank et al. have described a clear correlation between TPC treatment, healthy gut microbial communities, and prevention of arthritis [111,119]. Such studies that characterize and manipulate the microbiome associated with autoimmune diseases may have great potential as diagnostic and therapeutic tools, respectively.

Shemer presented an update about the usage of intravenous immunoglobulins (IVIg) in autoimmune and inflammatory conditions. This therapeutic agent modulates the immune system in multiple mechanism, thus beneficial in a wide range of disorders [120]. In Israel, data have been accumulated regrading using IVIg in treating many autoimmune diseases such as: systemic lupus erythematosus (SLE), anti-phospholipid syndrome (APS), multiple sclerosis, systemic sclerosis and more [121,122]. Regarding the adverse events, they are mostly mild and transient, whereas serious adverse reaction are relatively rare and may be predicted [123]. The consumption of IVIg worldwide is steadily growing, as currently it is used mainly for off-labeled indications.

Physical exercise is has a well-known influence on human health, and recently it has been found to exert effects on the immune system. Shapiro has shown that the incidence of Inflammatory Bowl Diseases (IBD) is higher in individuals who fail to conduct regular sport activity. It seems that there is a connection between skeletal muscles and intestinal microbiota, as has been shown in a study conducted in the Harvard Medical School [124]. This study showed that physical exercise causes an increase in production of IL-6 in muscle cells. IL- 6 in turn enhances fat oxidation and glucose utilization by phosphorylation of the enzyme $5^{\prime}$ adenosine monophosphate-activated protein kinase (AMPK). Furthermore, the increase in IL-6 levels is accompanied by increased production of anti-inflammatory cytokines [125]. From the microbim aspect, in IBD, there is a lower prevalence of Faecalibacterium prausnitzii. Physical exercises cause a greater variety of phyla
Firmicutes, including an increase in Faecalibacterium prausnitzii. In addition, Exercise increases the levels of butyrate [126]. Interestingly, the bacteria that produce butyrate are able to activate the AMPK enzyme. Also, Individuals who trained more often showed a significant increase in diversity [127].

It was the perfect setting in the historical city of Saint Petersburg for Goloviznin et al. to discussed somatic reincarnation of the human virtual nature. While before the 20th century the world of immunity was comprise from the field of metaphysics, It has shifted dramatically since the discovery of antibodies immune cells and phagocytosis [128]. Concepts such as "Self", "Non-self", "immune defense", "immune recognition," "immunological memory" are nowadays referred as immunoglobulins, cytokines, chemokines, integrins etc. Modern understanding can explain several immune processes, for example: "militaristic model of soldiers and weapons" can clarify the antimicrobial and antiviral immunity. However, the phenomenon of immunological tolerance requires other explanation. We have to remember that modern biomedicine represents only one side of the coin, and allow a more holistic paradigm in Immunology [129].

The congress ended with a focus on better management of administration of therapeutic agents. Edwards et al. presented strategies for effective drug dose reduction in the treatment of autoimmune conditions. He noted that today, drugs doses are based on trial and error experiments, in which a small range of doses is usually tested. It's important to note that these doses do not take into account the variation in patients' response [130]. The strategies presented were aimed in achieving the ideal serum and tissue concentration of drug and were based upon randomized controlled trials [131], responsive strategies [132] and real-world data [133].

\section{Summary}

In conclusion, looking through the presented works and data at the first Saint Petersburg annual meeting allowed the participants to obtain a reliable view of the most recent and upcoming evidence that might affect our practice in autoimmune diseases. After this meeting, clinicians became more familiar with the key role that diets (curcumin, capsaicin, chocolate and salt), adjuvants, viral agents and microbiome playing in promoting/protecting to/from the development of autoimmune diseases. Moreover, participants became more aware of the contribution of serological tests to the diagnosis and classification of autoimmune diseases. Therefore, we are convinced that this is the real added value of meetings which are capable of gathering researchers from different areas to provide a fertile field for contamination and future projects.

\section{Acknowledgements}

This work is supported by the grant of the Government of the Russian Federation for the state support of scientific research carried out under the supervision of leading scientists, agreement 14.W03.31.0009, on the basis of SPbU projects 15.34.3.2017 and 15.64.785.2017.

\section{References}

[1] Suki B, Bates JHT, Frey U. Complexity and emergent phenomena. Comprehensive physiology [internet]. John Wiley \& Sons, Inc.; 2011 Available from: http:// onlinelibrary.wiley.com/doi/10.1002/cphy.c100022/abstract.

[2] Alekseenko IV, Pleshkan VV, Monastyrskaya GS, Kuzmich AI, Snezhkov EV, Didych DA, et al. Fundamentally low reproducibility in molecular genetic cancer research. Russ J Genet Jul 2016;52(7):650-63.

[3] Coronel-Restrepo N, Posso-Osorio I, Naranjo-Escobar J, Tobón GJ. Autoimmune diseases and their relation with immunological, neurological and endocrinological axes. Autoimmun Rev Jul 2017:16(7):684-92.

[4] Kolev MV, Ruseva MM, Harris CL, Morgan BP, Donev RM. Implication of complement system and its regulators in Alzheimer's disease. Curr Neuropharmacol Mar 2009;7(1):1-8. 
[5] Zhang W, Wang L-Z, Yu J-T, Chi Z-F, Tan L. Increased expressions of TLR2 and TLR4 on peripheral blood mononuclear cells from patients with Alzheimer's disease. J Neurol Sci Apr 15 2012;315(1-2):67-71

[6] Pellicanò M, Larbi A, Goldeck D, Colonna-Romano G, Buffa S, Bulati M, et al. Immune profiling of Alzheimer patients. J Neuroimmunol Jan 18 2012;242(1-2): 52-9.

[7] Lueg G, Gross CC, Lohmann H, Johnen A, Kemmling A, Deppe M, et al. Clinical relevance of specific T-cell activation in the blood and cerebrospinal fluid of patients with mild Alzheimer's disease. Neurobiol Aging Jan 2015;36(1):81-9.

[8] St-Amour I, Cicchetti F, Calon F. Immunotherapies in Alzheimer's disease: too much, too little, too late or off-target? Acta Neuropathol (Berl) Apr 1 2016; 131(4):481-504

[9] Graus F, Delattre JY, Antoine JC, Dalmau J, Giometto B, Grisold W, et al. Recommended diagnostic criteria for paraneoplastic neurological syndromes. J Neurol Neurosurg Psychiatry Aug 2004;75(8):1135-40.

[10] Darnell RB, Posner JB. Paraneoplastic syndromes involving the nervous system. N Engl J Med Oct 16 2003;349(16):1543-54.

[11] Corsini E, Gaviani P, Chiapparini L, Lazzaroni M, Ciusani E, Bisogno R, et al. Intrathecal synthesis of onconeural antibodies in patients with paraneoplastic syndromes. J Neuroimmunol Jan 15 2016;290:119-22.

[12] Vollmer TL, McCarthy M. Autoimmune encephalitis: a more treatable tragedy if diagnosed early. Neurology May 3 2016;86(18):1655-6.

[13] Fraune J, Gerlach S, Rentzsch K, Teegen B, Lederer S, Affeldt K, et al. Multiparametric serological testing in autoimmune encephalitis using computer-aided immunofluorescence microscopy (CAIFM). Autoimmun Rev Oct 2016;15(10):937-42.

[14] Segal Y, Dahan S, Calabrò M, Kanduc D, Shoenfeld Y. HPV and systemic lupus Erythematosus: a mosaic of potential crossreactions. Immunol Res 2017;65(2): 564-71.

[15] Segal Y, Calabrò M, Kanduc D, Shoenfeld Y. Human papilloma virus and lupus: the virus, the vaccine and the disease. Curr Opin Rheumatol Jul 2017;29(4):331-42.

[16] Kanduc D, Shoenfeld Y. From HBV to HPV: designing vaccines for extensive and intensive vaccination campaigns worldwide. Autoimmun Rev Aug 2016;1.

[17] Relle M, Weinmann-Menke J, Scorletti E, Cavagna L, Schwarting A. Genetics and novel aspects of therapies in systemic lupus erythematosus. Autoimmun Rev Nov 2015;14(11):1005-18.

[18] Ca V, Q C, B L, A H, S S, Je S, et al. Antiphospholipid antibodies internalised by human syncytiotrophoblast cause aberrant cell death and the release of necrotic trophoblast debris. J Autoimmun Dec 2013;47:45-57.

[19] Mekinian A, Alijotas-Reig J, Carrat F, Costedoat-Chalumeau N, Ruffatti A, Lazzaroni MG, et al. Refractory obstetrical antiphospholipid syndrome: features, treatment and outcome in a European multicenter retrospective study. Autoimmun Rev Jul 2017;16(7):730-4.

[20] Bertolaccini ML Contento G, Lennen R, Sanna G, Blower PJ, Ma MT, et al Complement inhibition by hydroxychloroquine prevents placental and fetal brain abnormalities in antiphospholipid syndrome. J Autoimmun Dec 2016;75:30-8.

[21] Lefkou E, Mamopoulos A, Dagklis T, Vosnakis C, Rousso D, Girardi G. Pravastatin improves pregnancy outcomes in obstetric antiphospholipid syndrome refractory to antithrombotic therapy. J Clin Invest Aug 1 2016;126(8):2933-40.

[22] Derksen VFAM, Huizinga TWJ, van der Woude D. The role of autoantibodies in the pathophysiology of rheumatoid arthritis. Semin Immunopathol 2017;39(4): 437-46.

[23] Conigliaro P, Chimenti MS, Triggianese P, Sunzini F, Novelli L, Perricone C, et al. Autoantibodies in inflammatory arthritis. Autoimmun Rev Jul 2016;15(7):673-83.

[24] López-Hoyos M, Álvarez-Rodríguez L, Mahler M, Torices S, Calvo-Alén J, Villa I, et al. Anti-carbamylated protein antibodies in patients with ageing associated inflammatory chronic disorders. Rheumatol Oxf Engl Apr 2016;55(4):764-6.

[25] Navarro-Millán I, Darrah E, Westfall AO, Mikuls TR, Reynolds RJ, Danila MI, et al. Association of anti-peptidyl arginine deiminase antibodies with radiographic severity of rheumatoid arthritis in African Americans. Arthritis Res Ther Oct 22 2016;18: 241.

[26] Seaman A, Darrah E, Infantino M, Meacci F, Manfredi M, Benucci M, et al. Antipeptidyl-arginine deaminase 3 (PAD3) antibodies as a promising marker to measure joint damage in patients with rheumatoid arthritis. Autoimmun Rev Jul 2016;15(7):776-80.

[27] Shovman O. Prevalence of anti-DFS70 antibodies in patients with and without systemic autoimmune rheumatic diseases. Clin Exp Rheumatol 2017 Jul 27 [Epub ahead of print].

[28] Mahler M, Meroni PL, Andrade LE, Khamashta M, Bizzaro N, Casiano CA, et al. Towards a better understanding of the clinical association of anti-DFS70 autoantibodies. Autoimmun Rev Feb 2016;15(2):198-201.

[29] Damoiseaux J, Csernok E, Rasmussen N, Moosig F, van Paassen P, Baslund B, et al Detection of antineutrophil cytoplasmic antibodies (ANCAs): a multicentre European Vasculitis Study Group (EUVAS) evaluation of the value of indirect immunofluorescence (IIF) versus antigen-specific immunoassays. Ann Rheum Dis 2017; 76(4):647-53.

[30] Radice A, Bianchi L, Sinico RA. Anti-neutrophil cytoplasmic autoantibodies: methodological aspects and clinical significance in systemic vasculitis. Autoimmun Rev Feb 2013;12(4):487-95.

[31] Csernok E, Damoiseaux J, Rasmussen N, Hellmich B, van Paassen P, Vermeersch P, et al. Evaluation of automated multi-parametric indirect immunofluorescence assays to detect anti-neutrophil cytoplasmic antibodies (ANCA) in granulomatosis with polyangiitis (GPA) and microscopic polyangiitis (MPA). Autoimmun Rev Jul 2016;15(7):736-41.

[32] Steri M, Orrù V, Idda ML, Pitzalis M, Pala M, Zara I, et al. Overexpression of the cytokine BAFF and autoimmunity risk. N Engl J Med 2017;376(17):1615-26 [27].
[33] Cimaz R. Systemic-onset juvenile idiopathic arthritis. Autoimmun Rev Sep 2016; 15(9):931-4.

[34] van de Veen W, Stanic B, Wirz OF, Jansen K, Globinska A, Akdis M. Role of regulatory B cells in immune tolerance to allergens and beyond. J Allergy Clin Immunol Sep 2016;138(3):654-65.

[35] Sakkas LI, Bogdanos DP. Systemic sclerosis: new evidence re-enforces the role of B cells. Autoimmun Rev Feb 2016;15(2):155-61.

[36] Dumoitier N, Terrier B, London J, Lofek S, Mouthon L. Implication of B lymphocytes in the pathogenesis of ANCA-associated vasculitides. Autoimmun Rev Nov 2015; 14(11):996-1004.

[37] Vadasz Z, Goldeberg Y, Halasz K, Rosner I, Valesini G, Conti F, et al. Increased soluble CD72 in systemic lupus erythematosus is in association with disease activity and lupus nephritis. Clin Immunol Mar 1 2016;164:114-8.

[38] Vadasz Z, Toubi E. Semaphorin 3A - a marker for disease activity and a potentia putative disease-modifying treatment in systemic lupus erythematosus. Lupus Oct 1 2012;21(12):1266-70.

[39] Tao H, Lu L, Xia Y, Dai F, Wang Y, Bao Y, et al. Antitumor effector B cells directly kill tumor cells via the Fas/FasL pathway and are regulated by IL-10. Eur J Immunol Apr 1 2015;45(4):999-1009.

[40] Park MK, Jung YO, Lee S-Y, Lee SH, Heo YJ, Kim EK, et al. Amelioration of autoimmune arthritis by adoptive transfer of Foxp3-expressing regulatory B cells is associated with the Treg/Th17 cell balance. J Transl Med Jun 28 2016;14 [Internet] Available from: http://www.ncbi.nlm.nih.gov/pmc/articles/PMC4924280/.

[41] Shoenfeld Y, Isenberg DA. The mosaic of autoimmunity. Immunol Today Apr 1989; 10(4):123-6.

[42] Orbach H, ZANDMAN-GODDARD G, Amital H, Barak V, Szekanecz Z, Szucs G, et al Novel biomarkers in autoimmune diseases. Ann N Y Acad Sci 2007;1109(1): 385-400.

[43] Mathieu C. Vitamin D and the immune system: getting it right. IBMS BoneKey 2011;8(4):178-86

[44] Azrielant S, Shoenfeld Y. Eppur Si Muove: vitamin D is essential in preventing and modulating SLE. Lupus May 1 2016;25(6):563-72.

[45] Smolen JS, Aletaha D, McInnes IB. Rheumatoid arthritis. The Lancet Oct 2016; 388(10055):2023-38.

[46] McInnes IB, Schett G. Pathogenetic insights from the treatment of rheumatoid arthritis. The Lancet 2017;389(10086):2328-37.

[47] Robinson WH, Mao R. Biomarkers to guide clinical therapeutics in rheumatology? Curr Opin Rheumatol 2016;28(2):168

[48] Cuppen BVJ, Welsing PMJ, Sprengers JJ, Bijlsma JWJ, Marijnissen ACA, van Laar JM, et al. Personalized biological treatment for rheumatoid arthritis: a systematic review with a focus on clinical applicability. Rheumatology 2015;55(5):826-39.

[49] Tweehuysen L, van den Ende CH, Beeren FMM, Been EMJ, van den Hoogen FHJ, den Broeder AA. Little evidence for usefulness of biomarkers for predicting successful dose reduction or discontinuation of a biologic agent in rheumatoid arthritis: a systematic review. Arthritis Rheumatol Hoboken $\mathrm{Nj}$ 2017;69(2):301.

[50] Rodriguez-Pintó I, Espinosa G, Cervera R. Catastrophic antiphospholipid syndrome: the current management approach. Best Pract Res Clin Rheumatol 2016;30(2): 239-49.

[51] Espinosa G, Rodriguez-Pinto I, Cervera R. Catastrophic antiphospholipid syndrome: an update. Panminerva Med 2017.

[52] Rodríguez-Pintó I, Moitinho M, Santacreu I, Shoenfeld Y, Erkan D, Espinosa G, et al Catastrophic antiphospholipid syndrome (CAPS): descriptive analysis of 500 patients from the international CAPS registry. Autoimmun Rev Dec 2016;15(12): $1120-4$.

[53] Østensen M, Andreoli L, Brucato A, Cetin I, Chambers C, Clowse MEB, et al. State of the art: reproduction and pregnancy in rheumatic diseases. Autoimmun Rev 2015; 14(5):376-86

[54] D'Ippolito S, Gasbarrini A, Castellani R, Rocchetti S, Sisti LG, Scambia G, et al. Human leukocyte antigen (HLA) DQ2/DQ8 prevalence in recurrent pregnancy loss women. Autoimmun Rev 2016;15(7):638-43.

[55] Triggianese P, Perricone C, Chimenti MS, De Carolis C, Perricone R. Innate immune system at the maternal-fetal interface: mechanisms of disease and targets of therapy in pregnancy syndromes. Am J Reprod Immunol 2016;76(4):245-57.

[56] D'Aurizio F, Villalta D, Metus P, Doretto P, Tozzoli R. Is vitamin D a player or not in the pathophysiology of autoimmune thyroid diseases? Autoimmun Rev 2015; 14(5):363-9.

[57] Triggianese P, Watad A, Cedola F, Perricone C, Amital H, Giambini I. Vitamin D deficiency in an Italian cohort of infertile women. Am J Reprod Immunol 2017;78:4

[58] Балабанова РМ, Эрдес ШФ. Распространенность ревматических заболеваний в России в 2012-2013 гг. Научно-Практическая Ревматология 2015;53(2).

[59] Marzetti V, Breda L, Miulli E, Filippetti F, Mancini C, Chiarelli F, et al. Clinical characteristics of juvenile idiopathic arthritis in an area of central Italy: a populationbased study. Ann Ig Med Prev E Comunita 2017;29(4):281.

[60] Hiraki LT, Feldman CH, Liu J, Alarcón GS, Fischer MA, Winkelmayer WC, et al. Prevalence, incidence, and demographics of systemic lupus erythematosus and lupus nephritis from 2000 to 2004 among children in the US Medicaid beneficiary population. Arthritis Rheumatol 2012;64(8):2669-76.

[61] Kumar M, Chawla S, Jain A. Comparative study of anti-mutated citrullinated vimentin, anti-cyclic citrullinated peptides, and rheumatoid factor predictability in the diagnosis of rheumatoid arthritis. Int J Res Med Sci 2017;3(8):1949-52.

[62] Chalmers SA, Chitu V, Ramanujam M, Putterman C. Therapeutic targeting of macrophages in lupus nephritis. Discov Med 2015;20(108):43-9.

[63] Mohan C, Putterman C. Genetics and pathogenesis of systemic lupus erythematosus and lupus nephritis. Nat Rev Nephrol 2015;11(6):329-41.

[64] Chalmers SA, Wen J, Shum J, Doerner J, Herlitz L, Putterman C. CSF-1R inhibition attenuates renal and neuropsychiatric disease in murine lupus. Clin Immunol 2016. 
[65] Chalmers SA, Doerner J, Bosanac T, Khalil S, Smith D, Harcken C, et al. Therapeutic blockade of immune complex-mediated glomerulonephritis by highly selective inhibition of Bruton's tyrosine kinase. Sci Rep 2016;6:26164.

[66] Katz-Agranov N, Zandman-Goddard G. The microbiome and systemic lupus erythematosus. Immunol Res 2017;65(2):432-7.

[67] López P, Sánchez B, Margolles A, Suárez A. Intestinal dysbiosis in systemic lupus erythematosus: cause or consequence? Curr Opin Rheumatol 2016;28(5):515-22.

[68] He Z, Shao T, Li H, Xie Z, Wen C. Alterations of the gut microbiome in Chinese patients with systemic lupus erythematosus. Gut Pathog 2016;8(1):64.

[69] Corrêa JD, Calderaro DC, Ferreira GA, Mendonça SMS, Fernandes GR, Xiao E, et al. Subgingival microbiota dysbiosis in systemic lupus erythematosus: association with periodontal status. Microbiome 2017:5(1):34

[70] Sfriso P, Ghirardello A, Botsios C, Tonon M, Zen M, Bassi N, et al. Infections and autoimmunity: the multifaceted relationship. J Leukoc Biol 2010;87(3):385-95.

[71] Arango M-T, Perricone C, Kivity S, Cipriano E, Ceccarelli F, Valesini G, et al. HLA DRB1 the notorious gene in the mosaic of autoimmunity. Immunol Res Feb 2017; 65(1):82-98.

[72] Cho JH, Feldman M. Heterogeneity of autoimmune diseases: pathophysiologic insights from genetics and implications for new therapies. Nat Med 2015; 21(7):730.

[73] Ballanti E, Perricone C, Greco E, Ballanti M, Di Muzio G, Chimenti MS, et al. Complement and autoimmunity. Immunol Res 2013;56(2-3):477-91.

[74] Scott D, Botto M. The paradoxical roles of $\mathrm{C} 1 \mathrm{q}$ and $\mathrm{C} 3$ in autoimmunity. Immunobiology 2016;221(6):719-25

[75] Jarrot P-A, Kaplanski G. Pathogenesis of ANCA-associated vasculitis: an update. Autoimmun Rev 2016;15(7):704-13.

[76] Ballanti E, Perricone C, di Muzio G, Kroegler B, Chimenti MS, Graceffa D, et al. Role of the complement system in rheumatoid arthritis and psoriatic arthritis: relationship with anti-TNF inhibitors. Autoimmun Rev 2011;10(10):617-23.

[77] Hawksworth OA, Li XX, Coulthard LG, Wolvetang EJ, Woodruff TM. New concepts on the therapeutic control of complement anaphylatoxin receptors. Mol Immunol 2017;89:36-43.

[78] Dahan S, Segal Y, Shoenfeld Y. Dietary factors in rheumatic autoimmune diseases: a recipe for therapy? Nat Rev Rheumatol 2017;13(6):348-58.

[79] Korneva EA, Rybakina EG, Shanin SN. Cellular, molecular and signaling mechanisms in neuro-immune interactions under stress. Adv Neuroimmune Biol 2012:2:300-5.

[80] Porcelli B, Pozza A, Bizzaro N, Fagiolini A, Costantini M-C, Terzuoli L, et al. Association between stressful life events and autoimmune diseases: a systematic review and meta-analysis of retrospective case-control studies. Autoimmun Rev Apr 2016;15(4):325-34.

[81] Korneva EA, Golovko OI, Kazakova TV. Molecular-biologic aspects of interaction between nervous and immune systems. Vopr Med Khim 1996;43(5):321-9.

[82] Korneva EA, Perekrest SV, Shainidze ZK. Central mechanisms of neuroimmune interactions and main questions to the future. Brain Behav Immun 2014;40:e1-

[83] Luigi BN, Watad A, Adawi M, Amital H, Aljadeff G, Shoenfeld Y. Adjuvants and autoimmunity: why do we develop autoantibodies, autoimmune diseases and lymphomas. Isr Med Assoc J IMAJ 2017;19(7):403.

[84] Pellegrino P, Clementi E, Radice S. On vaccine's adjuvants and autoimmunity: current evidence and future perspectives. Autoimmun Rev Oct 2015;14(10):880-8.

[85] Agmon-Levin N, Arango M-T, Kivity S, Katzav A, Gilburd B, Blank M, et al. Immunization with hepatitis B vaccine accelerates SLE-like disease in a murine model. J Autoimmun Nov 2014;54:21-32.

[86] Aratani S, Fujita H, Kuroiwa Y, Usui C, Yokota S, Nakamura I, et al. Murine hypothalamic destruction with vascular cell apoptosis subsequent to combined administration of human papilloma virus vaccine and pertussis toxin. Sci Rep Nov 112016 ; 6(1):36943.

[87] Goules AV, Tzioufas AG. Primary Sjögren's syndrome: clinical phenotypes, outcome and the development of biomarkers. Autoimmun Rev Jul 2016;15(7):695-703.

[88] Silva-Fernández L, Lunt M, Kearsley-Fleet L, Watson KD, Dixon WG, Symmons DP, et al. The incidence of cancer in patients with rheumatoid arthritis and a prior malignancy who receive TNF inhibitors or rituximab: results from the British Society for Rheumatology Biologics Register-Rheumatoid Arthritis. Rheumatology 2016; 55(11):2033-9.

[89] Tozzoli R, D'Aurizio F, Villalta D, Bizzaro N. Automation, consolidation, and integration in autoimmune diagnostics. Autoimmun Highlights 2015;6(1-2):1-6.

[90] Csernok E, Damoiseaux J, Rasmussen N, Hellmich B, van Paassen P, Vermeersch P, et al. Evaluation of automated multi-parametric indirect immunofluorescence assays to detect anti-neutrophil cytoplasmic antibodies (ANCA) in granulomatosis with polyangiitis (GPA) and microscopic polyangiitis (MPA). Autoimmun Rev 2016;15(7):736-41.

[91] Bizzaro N, Bossuyt X, Haapala A-M, Shoenfeld Y, Sack U. Accreditation in autoimmune diagnostic laboratories. A position paper of the European Autoimmunity Standardisation Initiative (EASI). Autoimmun Rev 2017;16(1):81-6

[92] Tozzoli R, Villalta D, Bizzaro N. Challenges in the standardization of autoantibody testing: a comprehensive review. Clin Rev Allergy Immunol 2017:53(1):68-77.

[93] Shovman O, Gilburd B, Chayat C, Lazar AD, Amital H, Blank M, et al. Anti-HMGCR antibodies demonstrate high diagnostic value in the diagnosis of immune-mediated necrotizing myopathy following statin exposure. Immunol Res 2017;65(1): 276-81.

[94] Musset L, Allenbach Y, Benveniste O, Boyer O, Bossuyt X, Bentow C, et al. AntiHMGCR antibodies as a biomarker for immune-mediated necrotizing myopathies: a history of statins and experience from a large international multi-center study. Autoimmun Rev 2016;15:983-93.

[95] Tozzoli R, Bonaguri C, Melegari A, Antico A, Bassetti D, Bizzaro N. Current state of diagnostic technologies in the autoimmunology laboratory. Clin Chem Lab Med 2013;51:129-38.
[96] Damoiseaux J, Andrade LE, Fritzler MJ, Shoenfeld Y. Autoantibodies 2015: from diagnostic biomarkers toward prediction, prognosis and prevention. Autoimmun Rev January 2016;2015:1-9.

[97] Wang L, Wang FS, Gershwin ME. Human autoimmune diseases: a comprehensive update. J Intern Med 2015;278:369-95.

[98] Nasonov EL, Aleksandrova EN, Novikov AA. Autoimmune rheumatic diseases problems of immunopathology and personalized treatment. Vestn Ross Akad Med Nauk 2015(2):169-82.

[103] Watad A, David P, Brown S, Shoenfeld Y. Autoimmune/inflammatory syndrome induced by adjuvants and thyroid autoimmunity. Front Endocrinol 2016;7.

[104] Churilov L, Stroev YI, Serdyuk IY, Kaminova-Mudzhikova O, Belyaeva I, Gvozdetsky A, et al. Autoimmune thyroiditis: centennial jubilee of a social disease and its comorbidity. Pathophysiology 2014;21(2):135-45.

[106] Dahan S, Shor DB-A, Comaneshter D, Tekes-Manova D, Shovman O, Amital H, et al. All disease begins in the gut: celiac disease co-existence with SLE. Autoimmun Rev 2016;15(8):848-53.

[107] Levi EH, Watad A, Whitby A, Tiosano S, Comaneshter D, Cohen AD, et al. Coexistence of ischemic heart disease and rheumatoid arthritis patients-a case control study. Autoimmun Rev 2016;15(4):393-6.

[108] Shor DB-A, Dahan S, Comaneshter D, Cohen AD, Amital H. Does inflammatory bowel disease coexist with systemic lupus erythematosus? Autoimmun Rev 2016;15(11):1034-7.

[109] Watad A, Mahroum N, Whitby A, Gertel S, Comaneshter D, Cohen AD, et al. Hypothyroidism among SLE patients: case-control study. Autoimmun Rev 2016;15(5): 484-6.

[110] Pitlik SD, Koren O. How holobionts get sick-toward a unifying scheme of disease. Microbiome 2017;5(1):64.

[111] Shamriz O, Mizrahi H, Werbner M, Shoenfeld Y, Avni O, Koren O. Microbiota at the crossroads of autoimmunity. Autoimmun Rev 2016;15(9):859-69.

[112] Shor DB-A, Harel M, Eliakim R, Shoenfeld Y. The hygiene theory harnessing helminths and their ova to treat autoimmunity. Clin Rev Allergy Immunol 2013; 45(2):211.

[113] Versini M, Bizzaro G, Shoenfeld Y. Helminths and autoimmunity: the good, the bad and the ugly. Isr Med Assoc J IMAJ 2015;17(4):249-50.

[114] Versini M, Jeandel P-Y, Bashi T, Bizzaro G, Blank M, Shoenfeld Y. Unraveling the hygiene hypothesis of helminthes and autoimmunity: origins, pathophysiology, and clinical applications. BMC Med 2015;13(1):81.

[115] Bashi T, Bizzaro G, Ben-Ami Shor D, Blank M, Shoenfeld Y. The mechanisms behind helminth's immunomodulation in autoimmunity. Autoimmun Rev Feb 2015; 14(2):98-104.

[116] Bashi T, Blank M, Shor DB-A, Fridkin M, Versini M, Gendelman O, et al. Successful modulation of murine lupus nephritis with tuftsin-phosphorylcholine. J Autoimmun 2015;59:1-7.

[117] Bashi T, Shovman O, Fridkin M, Volkov A, Barshack I, Blank M, et al. Novel therapeutic compound tuftsin-phosphorylcholine attenuates collagen-induced arthritis. Clin Exp Immunol 2016;184(1):19-28.

[118] Shor DB-A, Bashi T, Lachnish J, Fridkin M, Bizzaro G, Barshak I, et al. Phosphorylcholine-tuftsin compound prevents development of dextransulfate-sodium-salt induced murine colitis: implications for the treatment of human inflammatory bowel disease. J Autoimmun 2015;56:111-7.

[119] Ben-Amram H, Bashi T, Werbner N, Neuman H, Fridkin M, Blank M, et al. Tuftsinphosphorylcholine maintains normal gut microbiota in collagen induced arthritic mice. Front Microbiol 2017;8.

[120] Zuercher AW, Spirig R, Baz Morelli A, Käsermann F. IVIG in autoimmune disease - potential next generation biologics. Autoimmun Rev Aug 2016; 15(8):781-5.

[121] Katz U, Kishner I, Magalashvili D, Shoenfeld Y, Achiron A. Long term safety of IVIg therapy in multiple sclerosis: 10 years experience. Autoimmunity Sep 7 2006; 39(6):513-7.

[122] Zandman-Goddard G, Krauthammer A, Levy Y, Langevitz P, Shoenfeld Y. Long-term therapy with intravenous immunoglobulin is beneficial in patients with autoimmune diseases. Clin Rev Allergy Immunol 2012;42(2):247-55.

[123] Cherin P, Marie I, Michallet M, Pelus E, Dantal J, Crave JC, et al. Management of adverse events in the treatment of patients with immunoglobulin therapy: a review of evidence. Autoimmun Rev 2016;15(1):71-81.

[124] Bäckhed F, Manchester JK, Semenkovich CF, Gordon JI. Mechanisms underlying the resistance to diet-induced obesity in germ-free mice. Proc Natl Acad Sci 2007; 104(3):979-84.

[125] Fischer CP. Interleukin-6 in acute exercise and training: what is the biological relevance? Exerc Immunol Rev 2006;12(115):6-33

[126] Matsumoto M, Inoue R, Tsukahara T, Ushida K, Chiji H, Matsubara N, et al. Voluntary running exercise alters microbiota composition and increases n-butyrate concentration in the rat cecum. Biosci Biotechnol Biochem 2008;72(2):572-6.

[127] Clarke SF, Murphy EF, O'Sullivan O, Lucey AJ, Humphreys M, Hogan A, et al. Exercise and associated dietary extremes impact on gut microbial diversity. Gut 2014; 63(12):1913-20.

[128] Tauber A. Metchnikoff's radicalism. Clin Pathophysiol 2016;23(3):28-37.

[129] Nuryanti Wiendu. Scale and locational effects on tourism multipliers: tourism and regional development in Indonesia. Diss. Bournemouth University; 1998.

[130] Edwards CJ, Fautrel B, Schulze-Koops H, Huizinga TWJ, Kruger K. Dosing down with biologic therapies: a systematic review and clinicians' perspective. Rheumatology 2017; 10:10-6.

[131] Smolen JS, Nash P, Durez P, Hall S, Ilivanova E, Irazoque-Palazuelos F, et al. Maintenance, reduction, or withdrawal of etanercept after treatment with etanercept and methotrexate in patients with moderate rheumatoid arthritis (PRESERVE): a randomised controlled trial. The Lancet 2013;381(9870):918-29. 
[132] Fautrel B, Pham T, Alfaiate T, Gandjbakhch F, Foltz V, Morel J, et al. Step-down strategy of spacing TNF-blocker injections for established rheumatoid arthritis in remission: results of the multicentre non-inferiority randomised open-label controlled trial $<\mathrm{i}>$ (STRASS: spacing of TNF-blocker injections in rheumatoid arthritis). Ann Rheum Dis 2015;75(1) [annrheumdis-2014-206696].

[133] Marks JL, Holroyd CR, Dimitrov BD, Armstrong RD, Calogeras A, Cooper C, et al. Does combined clinical and ultrasound assessment allow selection of individuals with rheumatoid arthritis for sustained reduction of anti-tumor necrosis factor therapy? Arthritis Care Res 2015;67(6):746-53.

[134] Hashimoto K, Mori M. Guidelines for the diagnosis and management of thyroid disease and their utility. Nihon rinsho. Japanese journal of clinical medicine 2012; 70(11):1857. 